\title{
Crystallography, Compositions, and Properties of White Layer by Wire Electrical Discharge Machining of Nitinol Shape Memory Alloy
}

\author{
J.F. Liu ${ }^{\mathrm{a}}$, Y.B. Guo ${ }^{\mathrm{a}, *}$, T.M. Butler ${ }^{\mathrm{b}}$, M.L. Weaver ${ }^{\mathrm{b}}$ \\ ${ }^{a}$ Dept. of Mechanical Engineering, The University of Alabama, Tuscaloosa, AL 35487 USA \\ ${ }^{b}$ Dept. of Metallurgical and Materials Eng., The University of Alabama, Tuscaloosa, AL 35487 USA
}

\begin{abstract}
Nitinol shape memory alloy (SMA) is very challenging to machine by conventional mechanical cutting. Wire electric discharge machining (wire-EDM) is an alternative process to machine Nitinol SMAs. The machined surface integrity is critical to product performance such as fatigue, corrosion, and wear, yet few studies have conducted a thorough investigation of the machined surface integrity, in particular white layer (WL). This work focuses on a comprehensive investigation on the crystallography, compositions, and properties of the white layer using transmission electron microscopy (TEM), X-ray diffraction (XRD), electron backscatter diffraction (EBSD), and nanoindentation. The WL by wire-EDM exhibits a porous and nonuniform bi-layered structure. The white layer of Nitinol by EDM is a crystalline structure instead of the traditionally believed amorphous solid. The upper portion of the WL consists of primarily the solid solution phase $(\mathrm{Cu}+\mathrm{Ni}+\mathrm{Zn})-\mathrm{FCC}$, while $\mathrm{Ti}_{2} \mathrm{O}_{3}$ and Nitinol austenite phases dominate the lower portion of the WL. The white layer shows less crystal plastic deformation than the bulk material, and refined grains with random orientation can be found in the WL. The nanohardness of the WL is much higher than that of the bulk material due to oxide hardening.
\end{abstract}

Keywords: White layer, microstructure, EDM, surface integrity

\footnotetext{
${ }^{*}$ Corresponding author. Tel.: +1 205348 2615; Fax: +1 2053486419.

E-mail address: yguo@eng.ua.edu (Y.B. Guo).
} 


\section{Introduction}

Compared to conventional mechanical cutting, wire-EDM is a competitive alternative process to machine difficult-to-cut materials including nickel-based superalloys, titanium alloys, hardened steels, conductive ceramics, and cemented carbides. The high temperature plasma melts and vaporizes the work material, and then the molten material is expelled by shocking pressure when the plasma channel collapses and is flushed away by the dielectric [1]. The process characteristics of contact free and force free between the wire/workpiece prevent severe tool wear and other issues inherent to mechanical cutting.

"White layer" (Fig. 1) refers to the phase-transformed recast layer formed on the machined surface. The white layer thickness may vary from $1-10 \mu \mathrm{m}$, which depends on the level of discharge energy. In electrical discharge machining, a thin white layer (showing white color of the recast layer under microscope) is formed through re-solidification of the molten materials via rapid quenching, which results in complex phase transformation and very different microstructure from the bulk. The white layer causes great concerns in machining industry since its microstructure and mechanical properties are not well understood, but may be critical to part functions such as fatigue, corrosion, and wear.

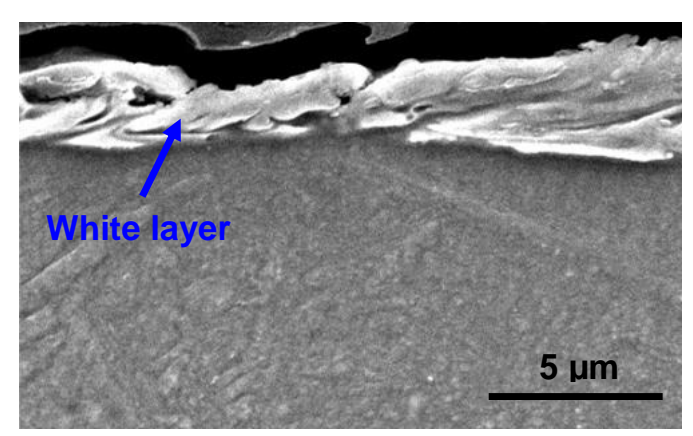

Fig. 1 White layer on the cross-section of wire-EDM NiTi sample.

In EDM processes, the main cut mode uses high discharge energy for rough cutting to increase material removal rate, while the trim cut mode uses low discharge energy for finish cutting to improve surface integrity. Klink et al. [2] and Li et al. [3] discovered that the white 
layers at the main cut mode exhibited a discontinuous and non-uniform microstructure when wire-EDM of ASP 23 tool steel and IN 718 alloys, and WLs were continuous and uniform at the finish trim cut mode. Liu et al. [4] showed that the WL thickness in wire-EDM of Nitinol SMAs can be significantly reduced at the finish trim cut mode. Klocke et al. [5] also reported that the average thickness of a white layer can be reduced using a decreased discharge energy in diesinking EDM of AISI 4140 steel.

Kruth et al. [6] found that the white layer consisted mainly of dendritic structures which were orientated in the same direction in EDMed mold steel Impax (Uddeholm). Cusanelli et al. [7] and Klocke et al. [5] observed the similar dendritic structure as well as columnar structure in the white layer by EDM of Böhler W300 ferritic steel and AISI 4140 steel. Kruth et al. [6] detected a large volume fraction of cementite $\left(\mathrm{Fe}_{3} \mathrm{C}\right)$ in the white layer via XRD when EDM of mould steel Impax with the oil dielectric. Rebolo et al. [8] also found cementite $\left(\mathrm{Fe}_{3} \mathrm{C}\right)$ in the white layer of EDMed steel in the oil dielectric. Qin et al. [9] found a new FCC structure which was likely a complex hydride of $\left(\mathrm{Ti}_{3} \mathrm{AlCr}\right)_{1-\mathrm{x}} \mathrm{H}_{\mathrm{x}}$ in the white layer of wire-EDMed Ti-46Al-2Cr ternary alloys in the water dielectric. Cusanelli et al. [7] found that the upper portion of the white layer consisted of residual austenite and the lower portion of the white layer was martensite in diesinking EDM of Böhler W300 ferritic steel. Hsieh et al. [10] observed the formation of several oxides $\left(\mathrm{TiO}_{2}, \mathrm{ZrO}_{2}\right.$ etc. $)$ in the white layer when machining $\mathrm{Ti}_{35.5} \mathrm{Ni}_{49.5} \mathrm{Zr}_{15}$ in the water dielectric. Klocke et al. [11] observed the amorphous solids in the upper portion of the white layer and crystalline structures in the lower portion of the white layer close to bulk materials in wireEDMed Vabadus 4 Extra tool steel at the finish trim cut mode.

The elemental compositions of the white layer may vary considerably due to the complex chemical reactions in the channel of high temperature plasma. Kruth et al. [6] detected saturated carbon in the white layer by XRD, which was diffused from the $\mathrm{CH}$-oil dielectric when EDM of mold steel Impax. Hsieh et al [10] and Li et al. [3] detected diffused oxygen in the white layer of wire-EDMed $\mathrm{Ti}_{35.5} \mathrm{Ni}_{49.5} \mathrm{Zr}_{15}$ and IN 718 in the water dielectric. Klocke et al. [12] observed that the white layer contained foreign elements $(\mathrm{O}, \mathrm{Cu}$, and $\mathrm{Zn})$ from the water dielectric and brass electrode in wire-EDMed WE43 magnesium alloys at the main cut mode, while foreign elements $(\mathrm{O}, \mathrm{Cu}$, and $\mathrm{Zn})$ were barely observed in the white layer at the finish trim cut mode. Guo et al. [13] and Liu et al. [4] found very little O element in the white layer when wire-EDM of Nitinol in water dielectric, but observed a trace of $\mathrm{Cu}$ and $\mathrm{Zn}$ elements (disused from the brass electrode) 
in the white layer at the finish cut mode. Klocke et al. [11] found that the white layer contained both foreign elements $\mathrm{Cu}$ and $\mathrm{Zn}$ (from the brass electrode) and allocated element Mo (from the carbides of the molten bulk materials) in wire-EDM of Vabadus 4 Extra tool steel at the finish trim cut mode with the oil-based dielectric.

Kruth et al. [6], Cusanelli et al. [7], and Klocke et al. [11] reported higher hardness of the white layers than the bulk in EDM of mold steel Impax, Böhler W300 ferritic steel, and Vabadus 4 Extra tool steel, respectively. Hsieh et al. [10] measured an increased hardness of the white layer in EDMed $\mathrm{Ti}_{35.5} \mathrm{Ni}_{49.5} \mathrm{Zr}_{15}$ shape memory alloys. The increased hardness of white layers was attributed to the formation of oxides and/or carbides. However, Li et al. [3] and Qu et al. [14] found the hardness of white layers were not higher than the bulk in EDM of Inconel 718 and WC-Co composites, respectively. Therefore, the hardness of white layer in EDM is material dependent. In general, the microhardness of white layer will be increased when EDM of carbonbased steels such as tool steels, while microhardness will not change or even decrease when EDM of carbon-free alloys such as Ti-/Ni-based alloys including Ti-6Al-4V and Inconel 718.

Rebelo et al. [8] and Ekmekci [15] showed tensile residual stress with the maximum magnitude in the subsurface in the white layer of EDMed martensitic steel and DIN 1.2738 mold steel, respectively. However, Klink et al. [2] found the maximum tensile residual stress on the surface and sharply decreased in the subsurface when wire-EDM of ASP 23 tool steel at trim cut mode, while the maximum tensile residual stress is in the subsurface at main cut mode. It also showed that the depth of tensile residual stress is about $30 \mu \mathrm{m}$ at main cut mode, while it is only 5-7 $\mu \mathrm{m}$ at finish trim cut mode. Furthermore, oil-based dielectric generally produced a much lower residual stress than that in the water-based dielectric. Antar et al. [16] showed that the tensile residual stress on the white layer surface was significantly reduced from $\sim 570 \mathrm{MPa}$ at main cut mode to $\sim 180 \mathrm{MPa}$ at finish cut mode in the wire-EDMed Udimet 720.

Although several studies have examined the morphology, microstructures, elemental compositions, hardness, and residual stress of the EDMed white layers, few studies shed light on the crystallography and properties of an EDMed white layer. A comprehensive study on the crystallography and properties of the white layer by EDM is critical. A white layer may have very different microstructures across the white layer due to the different quenching rates. There are also inconsistencies regarding the microstructure and hardness of the white layer in the literature. Furthermore, thermal damage to the grains within the heat affected zone (HAZ) is still 
unknown. Therefore, it is vital to clarify the crystallography and properties to understand the fundamental phenomena of the white layer.

This study will focus on the microstructures, crystallinity, and mechanical properties of white layers in wire-EDMed $\mathrm{Ni}_{50.8} \mathrm{Ti}_{49.2} \mathrm{SMA}$. The objectives are to: (1) identify the microstructure and crystallography of the white layers; (2) evaluate the thermal effect on crystallographic evolution in HAZ from main cut mode to finish trim cut mode; and (3) study the relationship between microstructure and properties of white layers.

\section{Experiment and Sample Preparation for Transmission Electron Microscopy (TEM)}

Wire-EDM experiments (Fig. 2) were performed with Mitsubishi FA20S Wire-EDM machine using a standard $250 \mu \mathrm{m}$ brass wire $(\mathrm{Cu}-36 \mathrm{Zn})$ in a DI-water dielectric. Nitinol $\mathrm{Ni}_{50.8} \mathrm{Ti}_{49.2}(50.8$ at.\% Ni-49.2 at.\% Ti) sheets with the dimension of $50 \mathrm{~mm}(\mathrm{~L}) \times 25 \mathrm{~mm}(\mathrm{~W}) \times$ $1.4 \mathrm{~mm}(\mathrm{H})$ were chosen as the workpiece (Table 1). Two types of samples were prepared in two methods: samples by only main cut mode and samples by main cut mode followed by four subsequent trim cut modes with reduced discharge energy according to the machine database. The machine parameters at each cutting mode were shown in Tables 2 and 3.
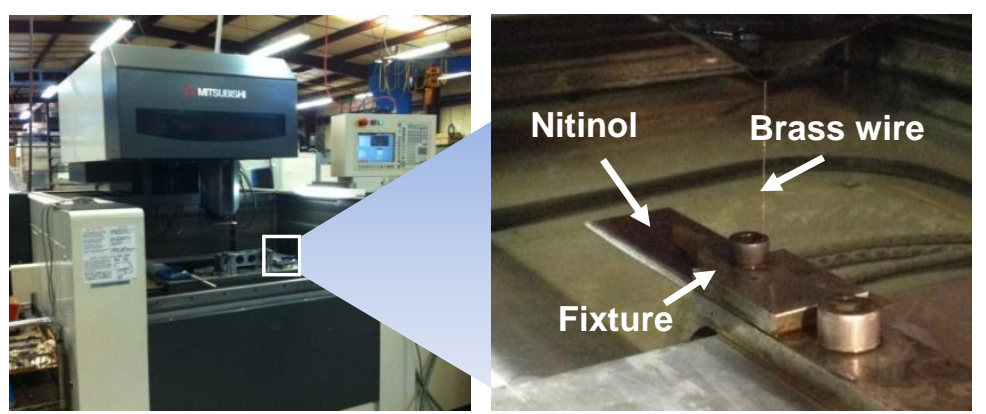

Fig. 2 Wire-EDM experimental setup.

Table 1 Composition of SE508 Nitinol

\begin{tabular}{ll}
\hline $\mathrm{Ni}$ (nominal) & 55.8 wt.\% \\
$\mathrm{Ti}$ & Balance \\
$\mathrm{O}(\max )$ & 0.05 wt.\% \\
$\mathrm{C}(\max )$ & 0.02 wt.\% \\
\hline
\end{tabular}


Table 2 Wire-EDM conditions

\begin{tabular}{lccccccccc}
\hline Cutting Mode & Vo & IP & OFF & SA & SB & VG & WT & LQ & FA \\
\hline Main cut mode & 16 & 6 & 1 & 4 & 12 & 42 & 11 & 14 & 0.13 \\
$1^{\text {st }}$ trim cut mode & 3 & 6 & 8 & 2 & 8 & 57 & 13 & 4 & 0.26 \\
$2^{\text {nd }}$ trim cut mode & 3 & 3 & 1 & 2 & 9 & 65 & 13 & 4 & 0.26 \\
$3^{\text {rd }}$ trim cut mode & 6 & 2 & 7 & 3 & 5 & 90 & 13 & 4 & 0.30 \\
Finish trim cut mode & 6 & 2 & 8 & 1 & 3 & 82 & 13 & 4 & 0.30 \\
\hline
\end{tabular}

Table 3 Description of specific parameters of wire-EDM machine

\begin{tabular}{ll}
\hline Parameter & Description \\
\hline Vo & Open-circuit voltage \\
IP & Intensity of power \\
OFF & Pulse interval time \\
SA & Second spark intensity \\
SB & Frequency of SA circuit \\
VG & Gap voltage during discharging \\
WT & Wire tension during machining \\
LQ & Liquid quantity \\
FA & Feedrate of electrode in cutting direction \\
\hline Note: The parameters are based on the Mitsubishi FA20S built-in database. \\
\hline
\end{tabular}

The EDMed samples at main cut mode were chosen for transmission electron microscopy (TEM) analysis since main cut has produced a thick white layer. To prepare a TEM specimen that is electron transparent ( 100 nm thickness), a variation of the focused ion beam (FIB) in-situ lift-out method was used for TEM foil preparation in an FEI Quanta 3D Dual Beam [17]. Fig. 3 shows the procedure of the initial lift-out and final thinning. First, a narrow Pt layer of $30 \mu \mathrm{m}$ (length) $\times 1 \mu \mathrm{m}$ (width) $\times 2 \mu \mathrm{m}$ (thickness) was deposited on the region of interest (ROI) to protect the sample against gallium contamination from the ion beam during milling (Fig. 3a). Secondly, a Ga ion beam was used to mill away trenches adjacent to the ROI (Fig. 3b). During 
the milling process, the ion beam parameters were $30 \mathrm{keV}$ and $3 \mathrm{nA}$. Once the trenches were deep enough $(5-6 \mu \mathrm{m})$, the sample $(\sim 1 \mu \mathrm{m}$ thick) was lifted out by welding the piece to a micromanipulator. The sample was then handled using the micro-manipulator and welded to a prefabricated $\mathrm{Cu}$-grid as shown in Fig. 3c. Subsequently, the $\sim 1 \mu \mathrm{m}$ thick specimen was thinned from each side to the desired thickness of $\sim 100 \mathrm{~nm}$ with a reduced beam current of 0.3 to $0.1 \mathrm{nA}$ (Fig. 3d). Finally, the specimen was cleaned by ion beam using $5 \mathrm{keV}$ and $0.23 \mathrm{nA}$.
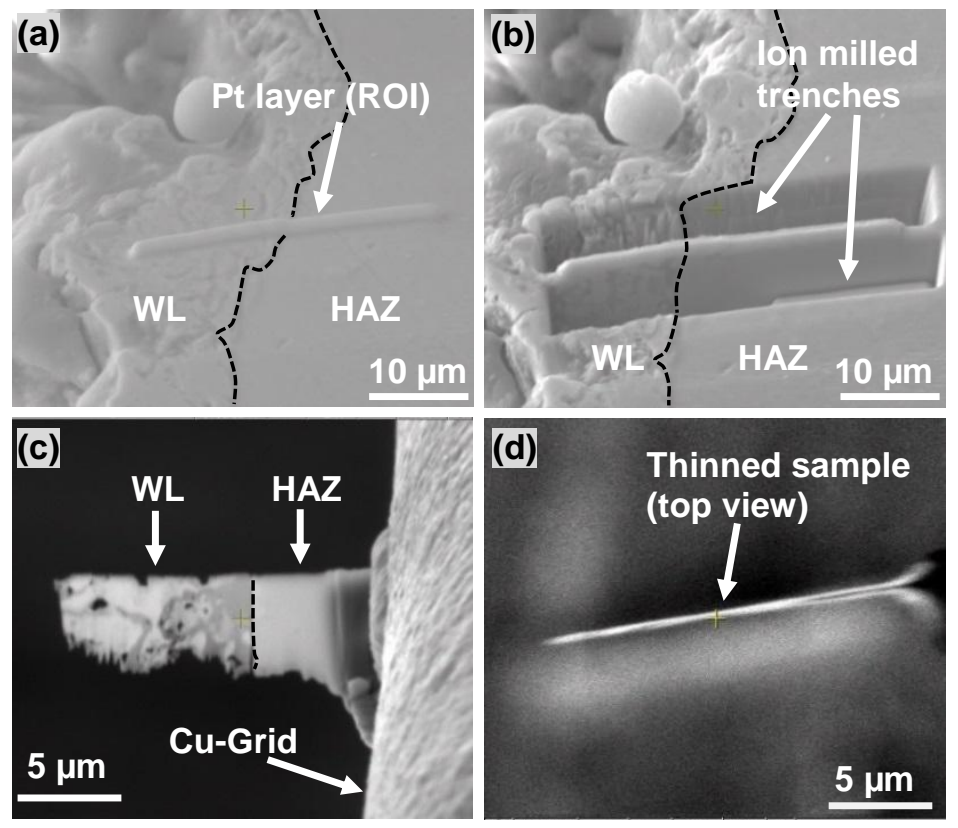

Fig. 3 TEM sample preparation: (a) deposition of Pt protection layer; (b) ion milling; (c) sample lift-out; (d) final thinning.

The scanning transmission electron microscopy high angle annular dark field (STEMHAADF) images, energy dispersive X-ray spectroscopy (EDS) data, and selected area electron diffraction patterns (SADPs) were captured using an FEI Tecnai F-20 Supertwin (S)TEM operated at $200 \mathrm{keV}$. The EDS data was analyzed using FEI ES Vision software with a thickness correction [18]. The SADPs were captured using a diffraction camera and analyzed in digital format. To verify the experimental crystallographic findings, all relevant crystals were simulated using a combination of Crystal Maker ${ }^{\mathrm{TM}}$, Single Crystal ${ }^{\mathrm{TM}}$, and Crystal Diffract ${ }^{\mathrm{TM}}$ software packages [19-21]. 
Also, X-ray diffraction (XRD) spectra of the machined surface and bulk materials were collected through a range of $20^{\circ}$ to $110^{\circ}$ (2 $\theta$ angle) using a Phillips X'Pert MPD XRD with $\mathrm{Cu}-$ $\mathrm{K} \alpha$ radiation $(\lambda=0.154056 \mathrm{~nm})$ at $45 \mathrm{kV}$ and $40 \mathrm{~mA}$. All relevant crystals were simulated in Crystal Maker ${ }^{\mathrm{TM}}$ and Crystal Diffract ${ }^{\mathrm{TM}}$ to generate theoretical XRD spectra using the experimental lattice parameters.

\section{Results and Discussion}

\subsection{Crystallography and Microstructure of White Layer}

\subsubsection{STEM-HAADF analysis}

STEM-HAADF imaging is a technique that generates atomic contrast images by interpreting highly scattered electrons collected with an annular detector. Therefore, contrast variations in STEM-HAADF images represent the variations in average atomic number (Z). In other words, bright contrast represents a high average atomic number $(\mathrm{Z})$ region, and darker contrast infers a lower average atomic number $(Z)$. Fig. 4 shows the STEM-HAADF images of the WL revealing the presence of a high atomic number (Z) phase (denoted as "bright phase") randomly interwoven with a low atomic number $(Z)$ phase (denoted as "dark phase"). The inhomogeneous WL microstructure has two distinct portions. The upper portion was dominated by bright phases and lower portion by dark phases. The duplex structure in the white layer was also observed in die-sinking EDMed Böhler W300 ferritic steel [7]. The different phases in the white layer might result from the temperature variation and/or compositional variation in the EDM process. In addition, the higher magnification images reveal nanoscale internal precipitates in both upper and lower portions. There is also a large distribution of voids, which shows the micro porosity formed during the EDM process. 

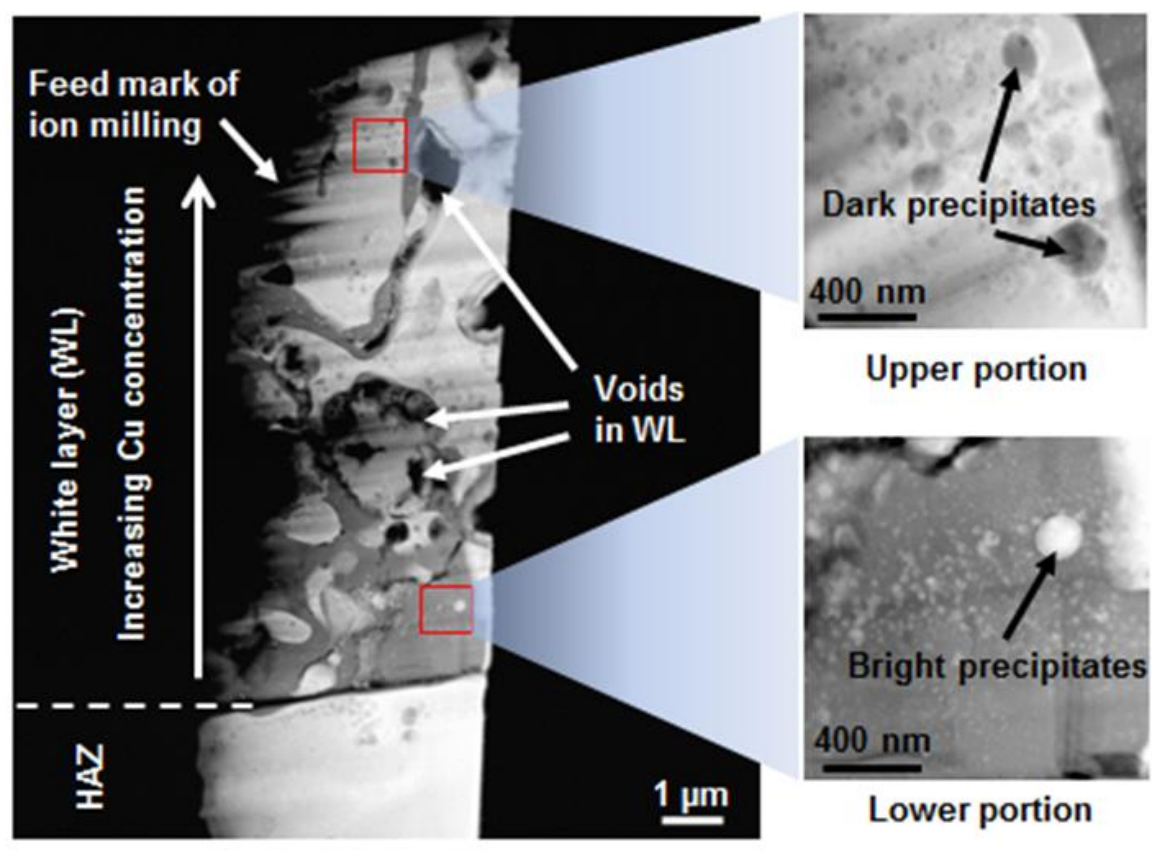

Upper portion

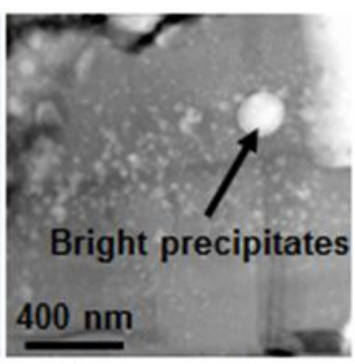

Lower portion

Fig. 4 STEM-HAADF image of the white layer at main cut mode.

\subsubsection{EDS analysis}

Energy dispersive X-ray spectroscopy (EDS) is an analytical technique for the elemental analysis. EDS data from the dark and bright phases is summarized in Fig. 5. The dark phases consist almost entirely of $\mathrm{Ti}$ and $\mathrm{O}$ in nearly a 40/60 ratio. This correlates well with the stoichiometry of $\mathrm{Ti}_{2} \mathrm{O}_{3}$. It is likely that the small amount of $\mathrm{Ni}, \mathrm{Cu}$, and $\mathrm{Zn}$ in the dark phases is due to the EDS interaction volume including other phases and/or internal precipitation. The bright phases contain very little $\mathrm{Ti}$ and $\mathrm{O}$, consisting primarily of $\mathrm{Ni}, \mathrm{Cu}$, and $\mathrm{Zn}$. The bright phases close to the HAZ contain higher concentrations of $\mathrm{Ni}$ while the bright phases away from HAZ exhibit much higher concentrations of $\mathrm{Cu}$ and $\mathrm{Zn}$. The bright phases close to the HAZ contain a higher concentration of $\mathrm{Ni}$ because there is a greater supply from the alloy. The bright phases away from the HAZ is close to the brass $(\mathrm{CuZn} 37)$ wire and, therefore, contain higher concentrations of $\mathrm{Cu}$ and $\mathrm{Zn}$ from the diffusion of the brass wire during EDM. It is likely that Ti and $\mathrm{O}$ detected in the bright phase are due to the electron/material interaction volume including some dark phases and/or internal precipitation. As for the nature of the bright phase, knowledge of the binary $\mathrm{Cu}-\mathrm{Zn}, \mathrm{Ni}-\mathrm{Cu}$, and $\mathrm{Ni}-\mathrm{Zn}$ alloy systems would lead to the prediction of an FCC solid solution phase. This inference is based on the vast solubility of $\mathrm{Zn}$ in both $\mathrm{Cu}$ and $\mathrm{Ni}$, as well as the full solid solubility of $\mathrm{Ni}$ in $\mathrm{Cu}$. 
The examination of cross-sectional view of the white layer leads to a more accurate and higher resolution analysis, which shows the predominance of the bright phase at the upper portion of the white layer. The higher resolution examination in this study also helps to clarify the $\mathrm{O}$ absence on the EDMed surface [4] in the literature, which the elemental composition was measured at the top of the white layer using EDS. Thus, it can be assumed that the data was primarily collected from the bright phases at the upper portion of the white layer (Fig. 4), which lacks O element.

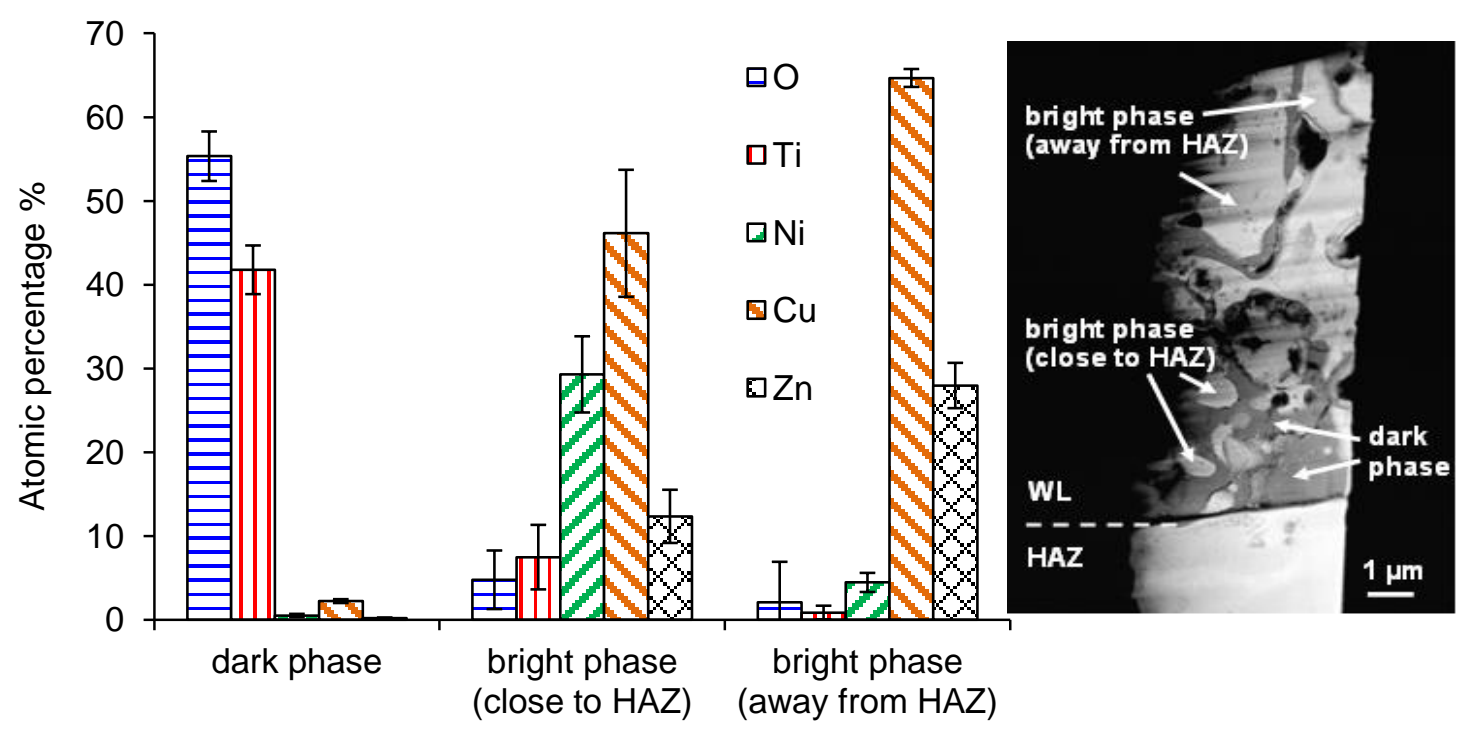

Fig. 5 EDS analysis of bright and dark phases in the white layer at main cut mode.

Fig. 6 shows the EDS data for the internal precipitates (Fig. 4) in both upper and lower portions of the white layer. For the dark precipitates in the upper portion of the white layer, large amounts of both $\mathrm{Ti}$ and $\mathrm{O}$ were detected. For the bright precipitates in the lower portion of the white layer, higher concentrations of $\mathrm{Cu}, \mathrm{Ni}$, and $\mathrm{Zn}$ were detected. Since the EDS interaction volume is much larger than the nanoscale precipitates in both cases, only an inference can be made on the chemistry of the precipitates. It is likely that the dark nanoscale precipitates are oxides, analogous to the larger $\mathrm{Ti}_{2} \mathrm{O}_{3}$ phases. However, based on the binary Ti-O phase diagram, other oxides like $\mathrm{TiO}$ or $\mathrm{TiO}_{2}$ may also be present. Similarly, it is plausible to suggest that the bright precipitates in the lower portion of the white layer could be FCC solid solution, analogous to the larger bright phases. Additional work with suitable techniques such as atom probe tomography is needed to further verify these inferences. 


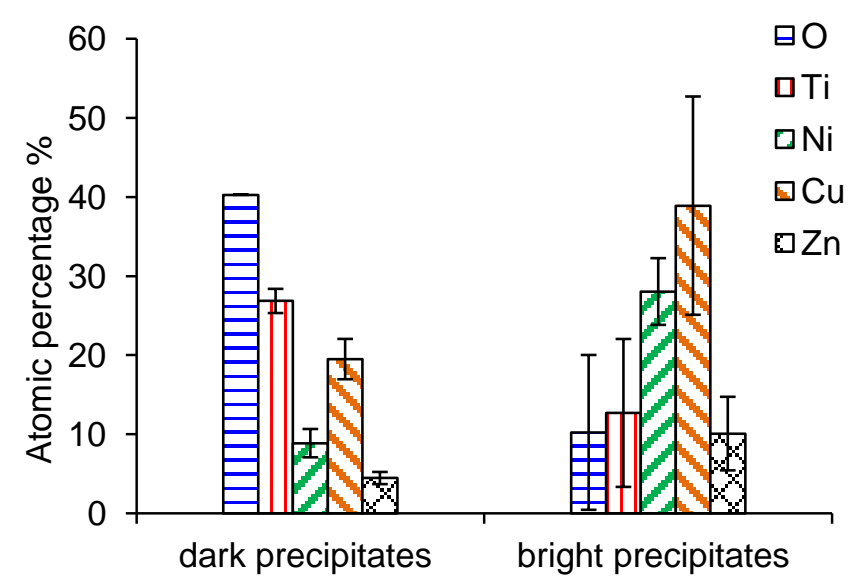

Fig. 6 EDS analysis of dark precipitates and bright precipitates in the white layer at main cut mode.

\subsubsection{TEM-SAD analysis}

Selected area diffraction (SAD) is an experimental technique performed in TEM to examine the crystallography of each phase. A TEM diffraction pattern is a $2 \mathrm{D}$ representation of $3 \mathrm{D}$ constructive interference of a crystalline lattice as interpreted from reciprocal space (inverse length). Each spot represents a plane, and a zone axis represents a common intersection between planes. By comparing the pattern and spot spacing in a simulated diffraction pattern, one can determine the crystal structure. SAD is referred to as "selected" because the use of apertures allows for the interpretation of diffraction beams from specific regions on the sample (i.e. a particular phase and/or precipitate). TEM-SAD experiments were performed on multiple bright and dark phases in the white layer to examine the crystallography of each phase. Thus, several selected area diffraction patterns (SADPs) were captured in each phase by tilting the sample to various orientations (Fig. 7). As hypothesized previously, the dark phase is consistent with the trigonal $\mathrm{R} \overline{3} \mathrm{c}$ (No. 167) $\mathrm{Ti}_{2} \mathrm{O}_{3}$ structure. Fig. 7 shows three SADPs taken from multiple dark phases in the white layer corresponding to the $\langle 210\rangle_{\mathrm{Ti} 2 \mathrm{O} 3}$ and $\langle 001\rangle_{\mathrm{Ti} 2 \mathrm{O} 3}$ type directions. The structure and lattice parameters calculated were consistent in all dark phases throughout the WL, identifying the dark phase to be $\mathrm{Ti}_{2} \mathrm{O}_{3}$. Interestingly, the lattice parameters calculated from the SADPs $(\mathrm{a}=\mathrm{b}=5.182 \AA, \mathrm{c}=13.995 \AA$ ) were slightly larger than the theoretical values $(\mathrm{a}=\mathrm{b}=$ $5.158 \AA$, and $c=13.611 \AA$ ). However, this unit cell dilation can be explained by the tensile residual stress induced in EDM. 

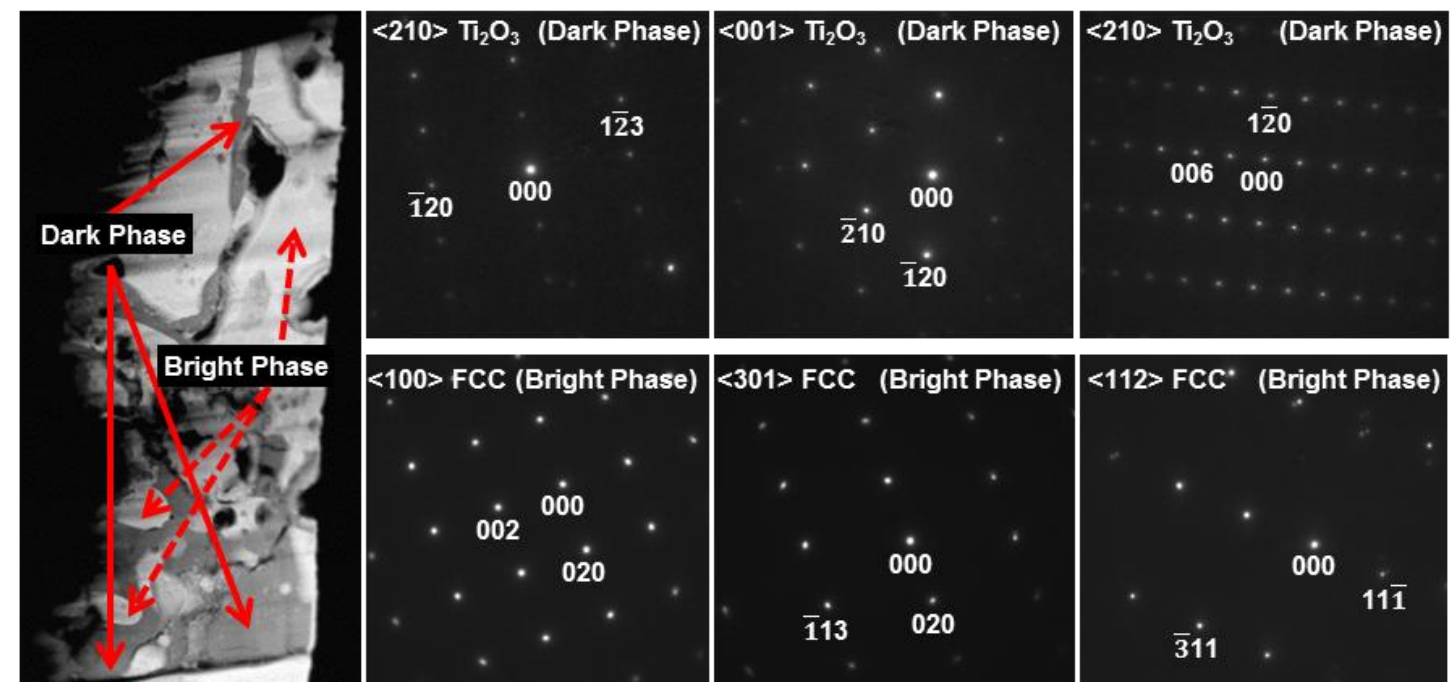

Fig. 7 Selected area diffraction patterns (SADPs) of the white layer at main cut mode: dark phase $\left(\mathrm{Ti}_{2} \mathrm{O}_{3}\right)$; bright phase $(\mathrm{Cu}+\mathrm{Ni}+\mathrm{Zn})-\mathrm{FCC}$ solid solution.

A similar analysis was performed on the bright phases in the white layer to determine the crystal structure. Again, multiple SADPs were obtained from several different bright phases in the white layer (Fig. 7). The bright phase is consistent with the cubic Fm $\overline{3} m$ (No. 225) FCC structure. This correlates well with the previous assumption that $\mathrm{Cu}, \mathrm{Ni}$, and $\mathrm{Zn}$ occupy a solid solution based on their extensive solubility for one another. Fig. 7 shows three SADPs taken from multiple bright phases in the white layer correlating to the $\langle 100\rangle_{\mathrm{FCC}},\langle 301\rangle_{\mathrm{FCC}}$, and $<112\rangle_{\text {FCC }}$ type directions. The lattice parameters varied based on location in the white layer. However, this can be explained by the compositional variability determined via EDS. It was found that the bright phases in the white layer containing higher concentrations of $\mathrm{Ni}$ (close to HAZ) exhibited a lattice parameter of $\mathrm{a}=3.726 \AA$, while in bright phases with higher concentrations of $\mathrm{Cu}$ and $\mathrm{Zn}$ (away from $\mathrm{HAZ}$ ), the lattice parameter was calculated to be slightly larger ( $\mathrm{a}=3.745 \AA$ ). From the metallurgical viewpoint, it is plausible to suggest that this small increase is due to the relative atomic radii differences between $\mathrm{Cu}, \mathrm{Ni}$, and $\mathrm{Zn}$. The regions with the larger lattice parameter contain higher concentrations of $\mathrm{Cu}$ and $\mathrm{Zn}$, which both exhibit slightly larger atomic radii in comparison to $\mathrm{Ni}$. When all of these elements are in solid solution, the increased amount of $\mathrm{Cu}$ and $\mathrm{Zn}$ can cause a dilation of the unit cell, indicative of a larger lattice parameter. 
The SADPs (Fig. 7) shows clear crystalline structures of the bright and dark phases in the white layer. However, this finding is in contrast to the recent report that amorphous solids were found in the white layer of wire-EDMed Vabadus 4 Extra tool steel [11]. The difference of the white layer structures is attributed to the compositional difference between Nitinol and steel. Inoue [22] indicated that amorphous solids are prone to form in multi-element alloys such as tool steels (usually more than 6 different elements) which have significantly different atomic sizes, but elements $(\mathrm{Cu}, \mathrm{Zn}, \mathrm{Ni})$ in the Nitinol white layer have very similar atomic size, and therefore, the Nitinol white layer didn't form amorphous solids. So, the microstructure of a white layer is determined by three major factors including the number of compositional elements, element atomic size, and quenching rate.

\subsubsection{XRD analysis}

Fig. 8 shows the XRD spectra collected from the machined surfaces at the main cut mode and the bulk material. For the $(\mathrm{Cu}+\mathrm{Ni}+\mathrm{Zn})$-FCC phase, the average lattice parameter based on the TEM-SAD results was used for simulation. The bulk material spectrum consists primarily of the Nitinol austenite phase. The spectrum from the machined surface at the main cut mode shows the same Nitinol austenite peaks, and also exhibits $\mathrm{Ti}_{2} \mathrm{O}_{3}$ and $(\mathrm{Cu}+\mathrm{Ni}+\mathrm{Zn})-\mathrm{FCC}$ peaks. $\mathrm{The}^{\mathrm{Ti}} \mathrm{O}_{3}$ and $(\mathrm{Cu}+\mathrm{Ni}+\mathrm{Zn})$-FCC peaks detected in the WL verifies the TEM-SAD results discussed in section 3.1.3. The Nitinol austenite peak detected in the machined surface at main cut mode could result from both WL and bulk materials, because the penetration depth by X-ray is large enough to enclose the white layer and bulk material beneath it. In addition, a slight peak shift of the Nitinol austenite phase is observed at main cut mode (e.g. $42.70^{\circ} @$ main cut mode vs. $42.26^{\circ} @$ bulk material), which indicates the existence of residual stress in the surface and subsurface. 


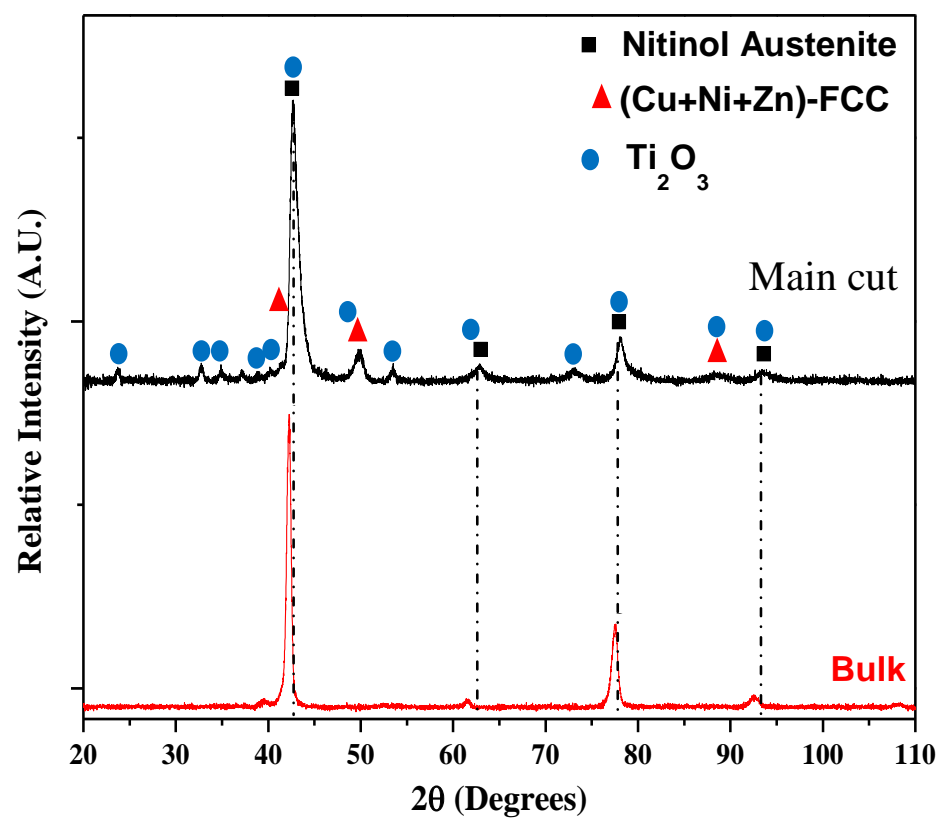

Fig. 8 X-ray diffraction spectra of bulk material and machined surfaces at main cut mode.

\subsubsection{EBSD analysis}

Electron backscatter diffraction (EBSD) is a microstructural-crystallographic technique to measure the crystallographic orientations of any crystalline material. EBSD images of the white layers were collected from the polished samples at both main cut and finish trim cut modes on a JOEL 7000 FE-SEM using OXFORD AZtec software. To ensure high quality signal/data, the samples were first ground by sandpaper up to 4000 grit, and then polished using diamond sprays up to a $0.25 \mu \mathrm{m}$ finish, and finally polished by $0.06 \mu \mathrm{m}$ colloidal silica in a vibratory polisher.

In EBSD, the Kikuchi patterns generated from each point of the sample surface are compared and indexed to the standard Kikuchi patterns of pre-defined phases. Thus, the specific phase and crystallographic orientation can be determined. With flexibility in defining the size of the scanning region, the phase distribution in the WL can be indexed via EBSD on a large scale, which is challenging with TEM analysis. Therefore, the crystals of the three major identified phases in the WL $\left(\mathrm{Ti}_{2} \mathrm{O}_{3},(\mathrm{Cu}+\mathrm{Ni}+\mathrm{Zn})-\mathrm{FCC}\right.$ and Nitinol austenite) were created in TWIST software using their experimentally determined crystal structures and lattice parameters. These simulated models were then imported into OXFORD AZtec software for EBSD scanning. Fig. 9 shows the EBSD maps of the white layer at the main cut mode. As shown in the SEM image (Fig. 9a), a typical white layer region was scanned with step size of $80 \mathrm{~nm}$. The identified phases 
were shown by phase color map (Fig. 9b), which indicates the phase distribution in the scanning region by assigning specific color to each individual phase. The black region indicates unindexed zones which are likely voids or different phases. It was found that the $(\mathrm{Cu}+\mathrm{Ni}+\mathrm{Zn})-\mathrm{FCC}$ and $\mathrm{Ti}_{2} \mathrm{O}_{3}$ phases dominated the white layer, closely resembling the TEM results. The $(\mathrm{Cu}+\mathrm{Ni}+\mathrm{Zn})-$ FCC phase was found primarily in the upper portion of the WL, while the $\mathrm{Ti}_{2} \mathrm{O}_{3}$ phase dominated the lower portion of the WL with a trace amount of Nitinol austenite. In addition, a large amount of refined grains as well as several voids and/or unindexed phases can be found in the upper portion of the WL, which resulted from the re-deposition and recrystallization of expelled materials by rapid quenching. The lower portion of the WL shows more uniform phases than the upper portion, which could result from the re-solidification of melting pool instead of recrystallization of expelled materials.

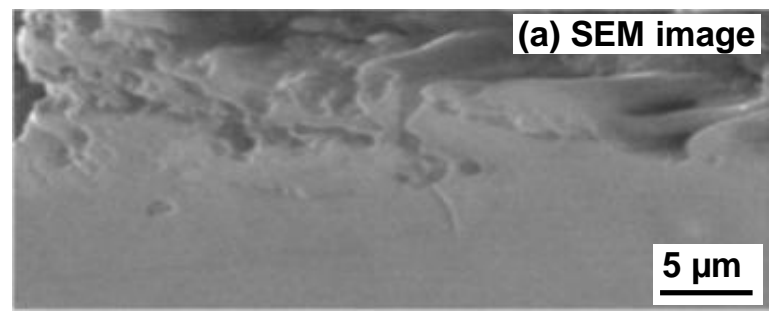

Scanned region

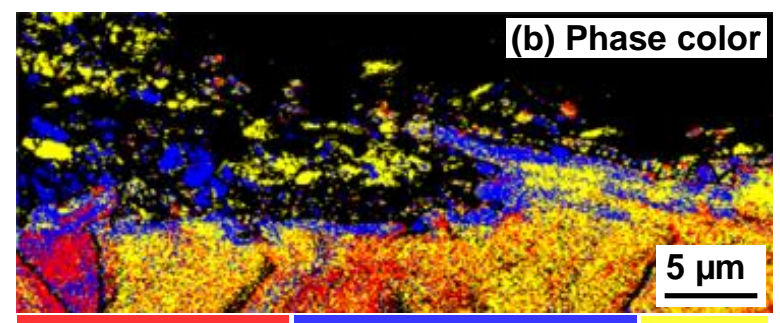

NiTi austenite $(\mathrm{Cu}+\mathrm{Ni}+\mathrm{Zn})-\mathrm{FCC} \quad \mathrm{Ti}_{2} \mathrm{O}_{3}$

Fig. 9 EBSD of the subsurface from main cut mode: (a) SEM image; (b) phase color.

\subsection{Crystallinity of Heat Affected Zone}

The heat affected zones (HAZs) of the EDMed samples at both main cut and finish trim cut modes were characterized by EBSD. Fig. 10 shows SEM images of the scanning regions for each HAZ. Literature has shown that there was little diffusion of foreign elements detected in the HAZs via EDS [3]. Thus, it is reasonable to examine only Nitinol austenite as the primary phase for HAZs when exploring crystallographic orientation. Two EBSD images (inverse pole figure and kernel average misorientation) were generated to characterize the crystallinity of each respective $\mathrm{HAZ}$. 

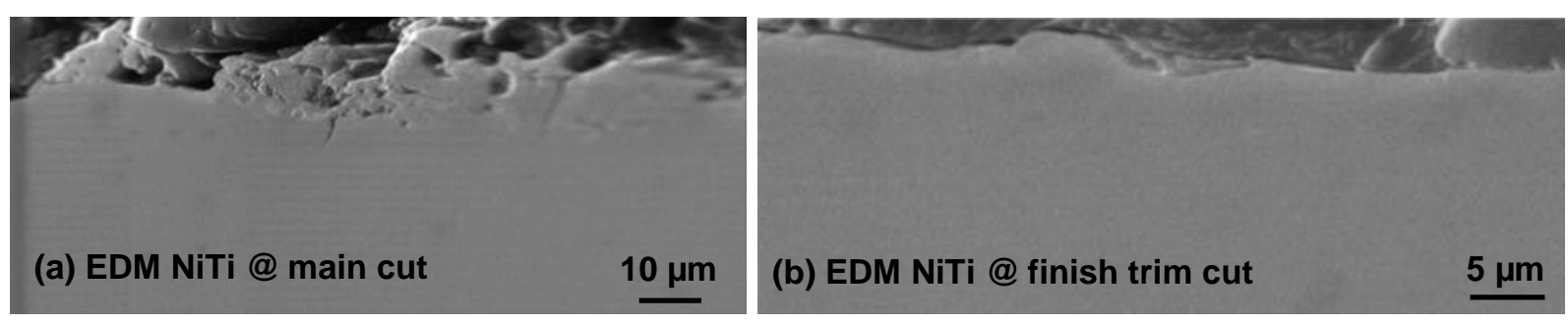

Fig. 10 SEM images of subsurface at main cut and finish trim cut modes.

\subsubsection{Grain orientation}

Fig. 11 shows the inverse pole figure (IPF) map for the subsurface cross-sections at main cut and finish trim cut modes. IPF map is a color coded map where the color gives an indication of the crystal direction aligned with the sample. Regions coded with similar color indicate the similar crystallographic orientation. Also, individual grains can be identified by different colors. For the subsurface cross-section at main cut mode, similar to the result in section 3.1.5, randomly oriented and significantly refined grains can be found in WL. In contrast, very few refined grains could be found in the subsurface cross-section due to the very thin white layer at finish trim cut mode.

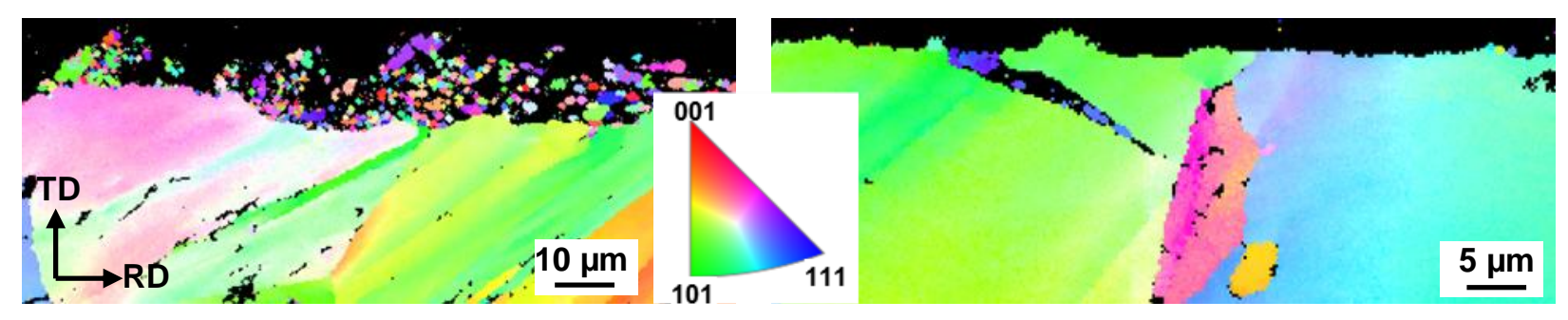

(a)EDMNiTi@ main cut

(b) EDM NiTi @ finish trim cut

Fig. 11 EBSD IPF-based maps along rolling direction (RD) in the subsurface at main cut and finish trim cut modes

The HAZ below the WL at main cut mode does not exhibit uniform color in each grain, but displays several narrow bands. The mechanism of the formation of narrow band is not clear yet, but the plastic deformation in HAZ could be a possible reason. Benafan [23] reported that the yield stress of NiTi austenite decreases with increasing temperature. Therefore, the high temperature and residual stress in the HAZ induced by EDM could lead to the plastic deformation and then contribute to the formation of narrow bands. In contrast, the HAZ in finish 
trim cut mode shows uniform color in each grain free of narrow bands. It can be explained that the temperature and residual stress in the HAZ are not high enough to cause plastic deformation due to the reduced discharge energy at finish trim cut mode.

\subsubsection{Crystal misorientation}

Kernel average misorientation (KAM) is a good indicator of strain in crystalline materials by measuring the average misorientation between the local point and all of the neighboring points. Fig. 12 shows the KAM maps of the subsurface cross-sections at both main cut and finish trim cut modes. At main cut mode, the misorientation of WL is smaller than that of the underlying HAZ. At finish trim cut mode, there is a uniform misorientation for each scanning point within $40 \mu \mathrm{m}$ in the subsurface, indicating no process induced plastic deformation was induced. This result is different from the literature that higher kernel average misorientation can be found in the WL and the subsurface when wire-EDM of the tool steel in the oil dielectric (Klocke et al., 2014). This could be explained by the use of a different work material and dielectric, thus modifying the microstructure of the WL and HAZ. Therefore, the process induced strain in wireEDM depends on the specific work material and dielectric.

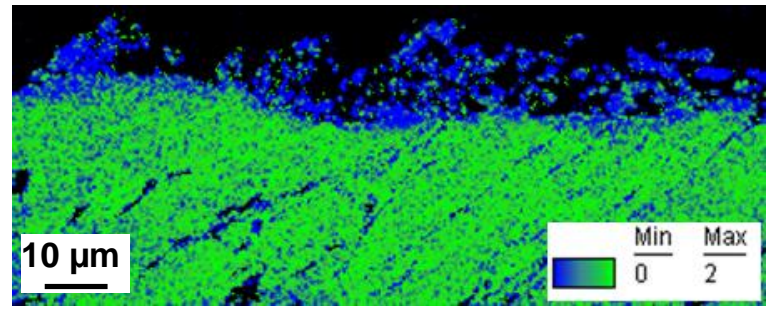

(a)EDM NiTi@main cut

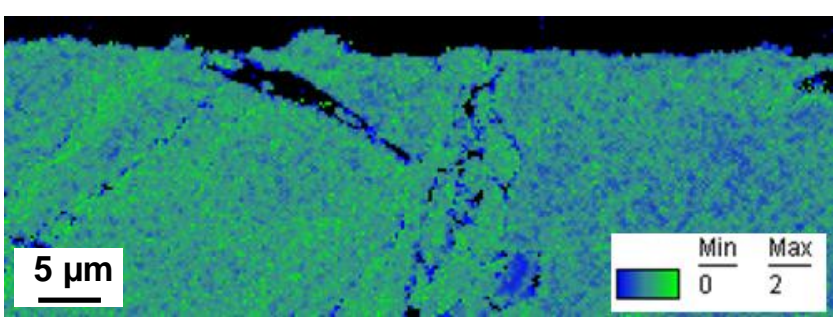

(b) EDM NiTi @ finish trim cut

Fig. 12 Kernel average misorientation in the subsurface at main cut and finish trim cut modes

\subsection{Mechanical Properties}

Nanohardness and elastic modulus of the samples were measured by nanoindentation using a HYSITRON TI 900 TriboIndenter. All indents were performed using a diamond Berkovich indenter (100 $\mathrm{nm}$ nose radius). For reliable measurement, the indentation was performed using a 
$3 \times 11$ matrix pattern as shown in Fig. 13. The row and column spacing of matrix were set at $5 \mu \mathrm{m}$ and $7 \mu \mathrm{m}$, respectively. The top row of the indents was located within $2 \mu \mathrm{m}$ below the machined surface. Triangle loading type with the maximum load of $1 \mathrm{mN}$ and total indenting period of 20 seconds was used for each measurement. The data were analyzed using the TriboView software based on calibrated tip area function.

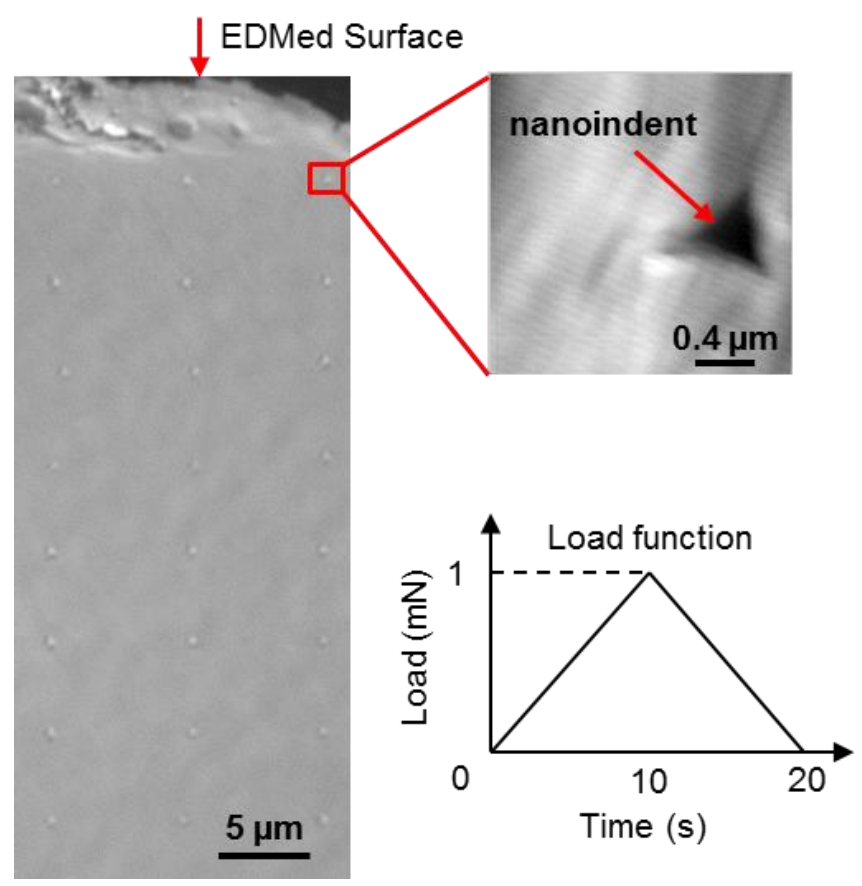

Fig. 13 Nanoindent matrix on the EDMed subsurface.

\subsubsection{Nanohardness}

Fig. 14 shows the variation of average nanohardness in the subsurfaces at both main cut and finish trim cut modes. At main cut mode, the nanohardness of the white layer $(7.93 \mathrm{GPa})$ is much higher than the bulk material $(5.29 \mathrm{GPa})$. This hardening is thought to result from oxide formation. The $\mathrm{Ti}_{2} \mathrm{O}_{3}$ phase in the WL induces a higher hardness than the base Nitinol austenite. The small dark and bright precipitates (Fig. 4) induced from rapid quenching in both upper and lower portions could also lead to the hardening of the white layer by inhibiting dislocation mobility.

The variation of nanohardness values in the WL at main cut mode likely results from its highly porous (non-uniform) structure. The solid regions exhibit a higher resistance to plastic deformation compared to the porous regions. Also, the nature of the duplex microstructure in the 
WL also contributes this variation in nanohardness. In particular, WL regions that are predominantly oxides will exhibit a hardness that is different than those regions consisting primarily of the $(\mathrm{Cu}+\mathrm{Ni}+\mathrm{Zn})-\mathrm{FCC}$ solid solution phase.

In contrast to main cut mode, the measured nanohardness for the subsurface at finish trim cut mode does not vary significantly within $50 \mu \mathrm{m}$ below the top surface. This infers that the top surface of the finish trim cut mode is relatively unaffected by the EDM processing.

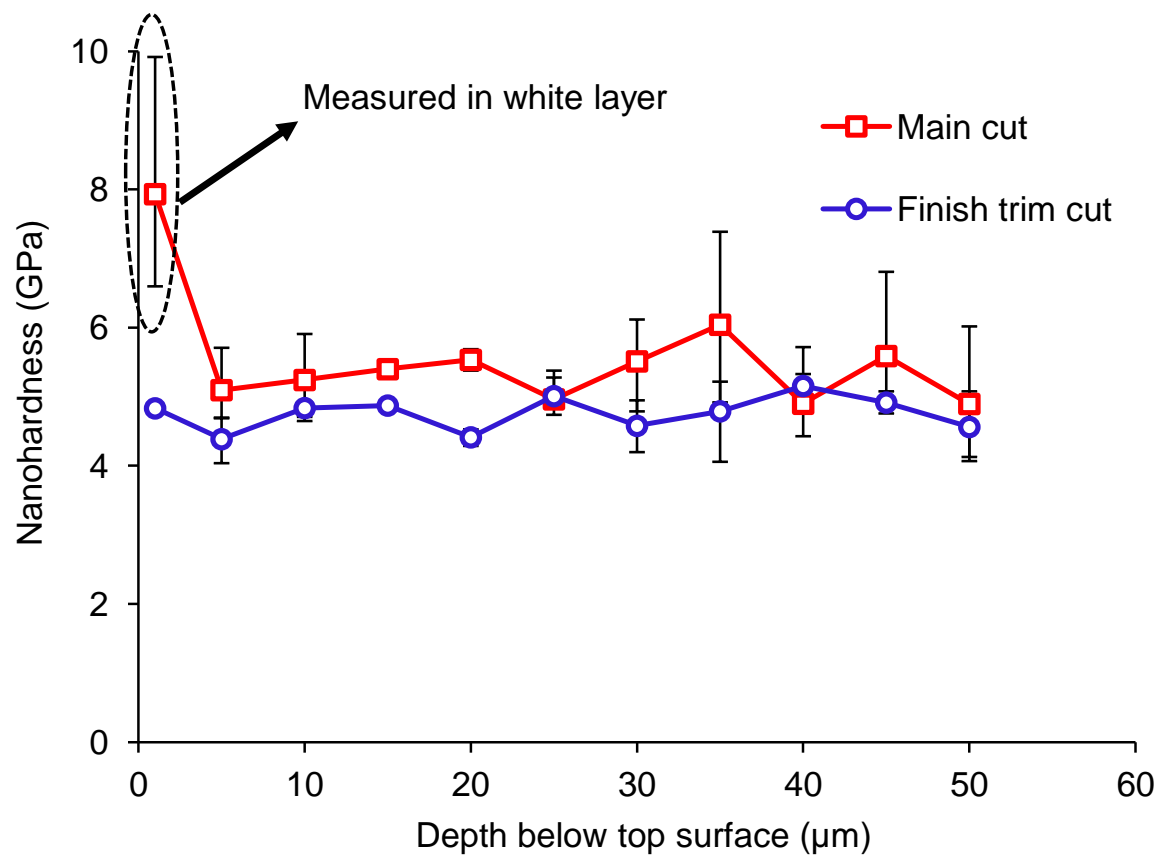

Fig. 14 Nanohardness profiles in the subsurface at main cut and finish trim cut modes.

\subsubsection{Reduced elastic modulus}

Fig. 15 shows the average reduced elastic modulus $\left(E_{r}\right)$ at main cut and finish trim cut modes. At the main cut mode, the WL does not show a significantly larger $E_{r}$ than the bulk material, which indicates that the large stiffness of surface material does not necessarily accompany the high nanohardness. Physically, the elastic modulus is a macroscopic manifestation of atomic bonding. The $E_{r}$ value is determined by the combination of bond bending and extension/compression at atomic level [25]. The HAZ shows a reduced $E_{r}$, which might result from the phase transformation induced by thermal damage. 


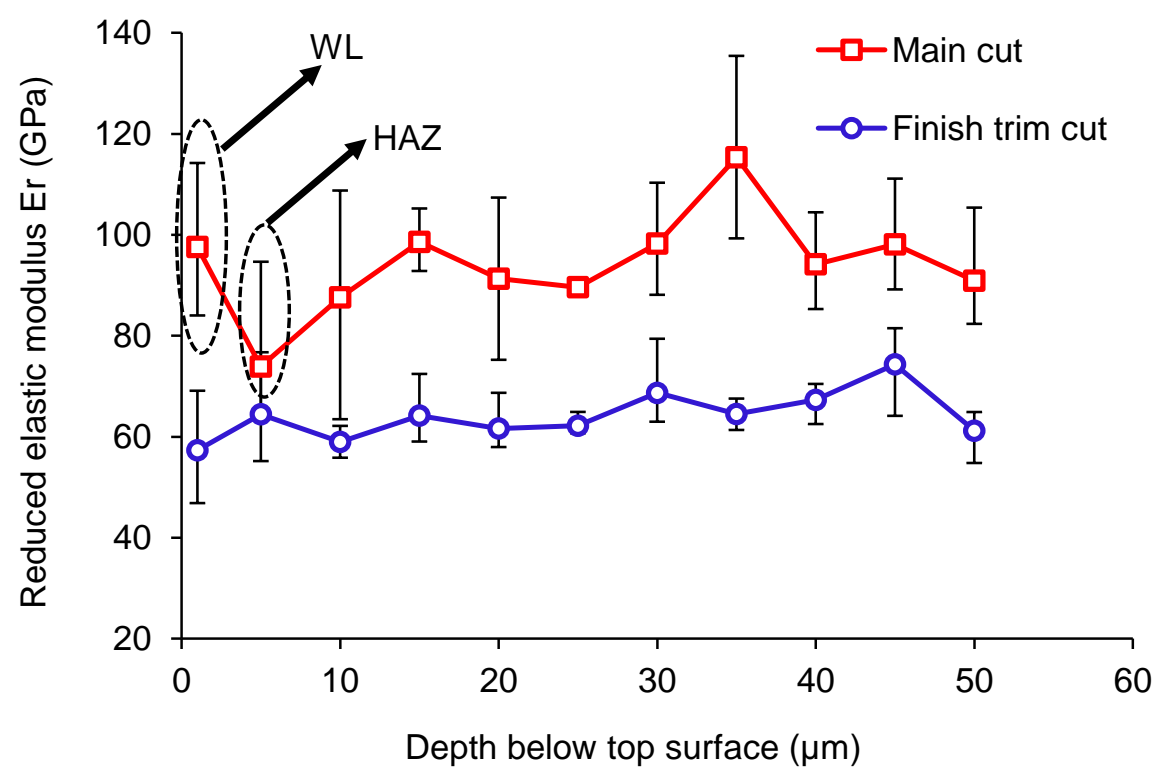

Fig. 15 Reduced elastic modulus profiles in the subsurface at main cut and finish trim cut modes.

At finish trim cut mode, the $E_{r}$ is also fairly constant in the subsurface, which represents uniform atomic bonding throughout the cross section. However, the average $E_{r}$ value of the finish trim cut subsurface is smaller than that of the main cut subsurface. This may be related to the crystal misorientation at the subsurface. Since the elastic modulus of Nitinol austenite is anisotropy, a higher average $E_{r}$ correlates to a higher degree of crystal misorientation at main cut mode as shown in Fig. 12a. Thus, a higher modulus for the main cut subsurface could be achieved. However, in the case of finish trim cut mode, the crystal misorientation is lower (Fig. $12 b)$, thus inherently lowering the overall modulus.

\section{Conclusions}

In this study, the microstructure and crystallography of the white layer (WL) and heat affected zone (HAZ) by wire-EDM of Nitinol were examined via TEM, XRD and EBSD, and the mechanical properties of wire-EDM induced subsurface were then investigated via nanoindentation. The WL formed during EDM Nitinol is a crystalline structure instead of an amorphous solid, which was attributed to the small number of element compositions of Nitinol and the small difference in atomic size for $\mathrm{Cu}, \mathrm{Zn}$, and $\mathrm{Ni}$ in the Nitinol white layer. The WL 
consists of two distinct portions with different chemistries and microstructures. The $(\mathrm{Cu}+\mathrm{Ni}+\mathrm{Zn})-\mathrm{FCC}$ solid solution phase primarily formed in the upper portion of the WL, while $\mathrm{Ti}_{2} \mathrm{O}_{3}$ and Nitinol austenite phases dominated the lower portion of the WL. As for mechanical properties of the WL, it shows smaller misorientation (i.e., less crystal plastic deformation) than the bulk. Refined grains with random orientation can be found in the WL. The nanohardness of the white layer is higher than the bulk due to oxide hardening, while the reduced elastic modulus is fairly consistent. In addition, the subsurface at main cut exhibits a higher modulus than finish trim cut, which is likely attributed to the higher degree of crystal misorientation in the subsurface at main cut.

\section{Acknowledgement}

The work was supported by the National Science Foundation CMMI \#1234696.

\section{References}

[1] W. König, F. Klocke, Manufacturing processes volume 3: removal, generation and laser material processing, Springer; 2007.

[2] A. Klink, Y.B. Guo, F. Klocke, Surface integrity evolution of powder metallurgical tool steel by main cut and finishing trim cuts in wire-EDM, Procedia Eng. 19 (2011) 178-183.

[3] L. Li, X.T. Wei, Y.B. Guo, W. Li, J.F. Liu, Surface integrity of Inconel 718 by wire-EDM at different energy modes, J. Mater. Eng. Perform. 23 (2014) 3051-3057.

[4] J.F. Liu, L. Li, Y.B. Guo, Surface integrity evolution from main cut mode to finish trim cut mode in W-EDM of shape memory alloy, Appl. Surf. Sci. 308 (2014) 253-260.

[5] F. Klocke, S. Schneider, L. Ehle, H. Meyer, L. Hensgen, A. Klink, Investigations on surface integrity of heat treated 42CrMo4 (AISI 4140) processed by sinking EDM, Procedia CIRP 42 (2016) 580-585.

[6] J-. Kruth, L. Stevens, L. Froyen, B. Lauwers, Study of the white layer of a surface machined by die-sinking electro-discharge machining, CIRP Ann. 44 (1995) 169-172. 
[7] G. Cusanelli, A. Hessler-Wyser, F. Bobard, R. Demellayer, R. Perez, R. Flükiger, Microstructure at submicron scale of the white layer produced by EDM technique, J. Mater. Process. Technol. 149 (2004) 289-295.

[8] J.C. Rebelo, A.M. Dias, D. Kremer, J.L. Lebrun, Influence of EDM pulse energy on the surface integrity of martensitic steels, J. Mater. Process. Technol. 84 (1998) 90-96.

[9] G.W. Qin, K. Oikawa, G.D.W. Smith, S.M. Hao, Wire electric discharge machining induced titanium hydride in Ti-46Al-2Cr alloy, Intermetallics 11 (2003) 907-917.

[10] S.F. Hsieh, S.L. Chen, H.C. Lin, M.H. Lin, S.Y. Chiou. The machining characteristics and shape recovery ability of $\mathrm{Ti}-\mathrm{Ni}-\mathrm{X}(\mathrm{X}=\mathrm{Zr}, \mathrm{Cr})$ ternary shape memory alloys using the wire electro-discharge machining, Int. J. Mach. Tools. Manuf. 49 (2009) 509-514.

[11] F. Klocke, L. Hensgen, A. Klink, L. Ehle, A. Schwedt, Structure and composition of the white layer in the wire-EDM process, Procedia CIRP 42 (2016) 673-678.

[12] F. Klocke, M. Schwade, A. Klink, D. Veselovac, A. Kopp, Influence of electro discharge machining of biodegradable magnesium on the biocompatibility, Procedia CIRP 5 (2013) 88-93.

[13] Y.B. Guo, A. Klink, C.H. Fu, J. Snyder, Machinability and surface integrity of Nitinol shape memory alloy, CIRP Ann. 62 (2013) 83-86.

[14] J. Qu, L. Riester, A.J. Shih, R.O. Scattergood, E. Lara-Curzio, T.R. Watkins, Nanoindentation characterization of surface layers of electrical discharge machined WCCo, Mater. Sci. Eng. A 344 (2003) 125-131.

[15] B. Ekmekci, Residual stresses and white layer in electric discharge machining (EDM), Appl. Surf. Sci. 253 (2007) 9234-9240.

[16] M.T. Antar, S.L. Soo, D.K. Aspinwall, C. Sage, M. Cuttell, R. Perez, et al., Fatigue response of Udimet 720 following minimum damage wire electrical discharge machining, Mater. Des. 42 (2012) 295-300.

[17] D. Tomus, H.P. Ng, In situ lift-out dedicated techniques using FIB-SEM system for TEM specimen preparation, Micron 44 (2013) 115-119.

[18] FEI-Company. FEI ES Vision software manual, 2004.

[19] D. Palmer, M. Conley, CrystalMaker for Windows version 2.0.7, CrystalMaker Software Ltd 2008.

[20] D. Palmer, M. Conley, SingleCrystal for Windows, 2010. 
[21] D. Palmer, M. Conley, Crystal Diffract for Windows, 2011.

[22] A. Inoue, High strength bulk amorphous alloys with low critical cooling rates (overview), Mater. Trans. JIM 36 (1995) 866-875.

[23] O. Benafan, R.D. Noebe, S.A. Padula, A. Garg, B. Clausen, S. Vogel, et al., Temperature dependent deformation of the B2 austenite phase of a NiTi shape memory alloy, Int. J. Plast. 51 (2013) 103-121.

[24] F. Klock, L. Hensgen, A. Klink, J. Mayer, A. Schwedt, EBSD-analysis of flexure hinges surface integrity evolution via wire-EDM main and trim cut technologies, Procedia CIRP 13 (2014) 237-242.

[25] T.H. Courtney, Mechanical behavior of materials, Waveland Press; 2005. 


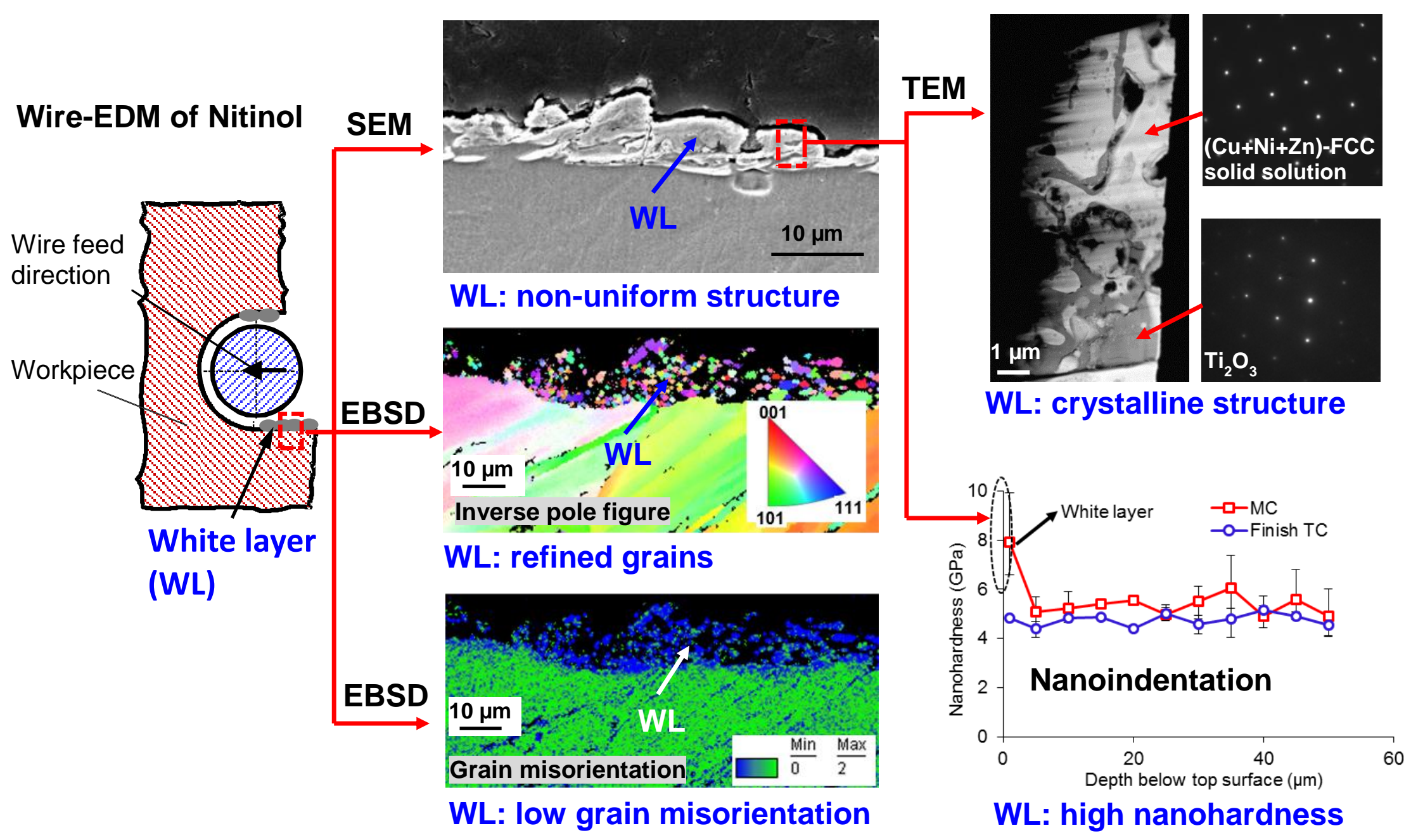

